\title{
Why do administrators employ or not employ support contacts? A Norwegian qualitative study
}

\author{
Aud Johannessen* \\ Ageing and Health \\ Norwegian Centre for Research, Education and Service Development \\ Tønsberg, Norway \\ Nordic School of Public Health NHV \\ Gothenburg, Sweden \\ Email: aud.johannessen@aldringoghelse.no \\ *corresponding author
}

\section{Anders Möller}

Nordic School of Public Health NHV

Gothenburg, Sweden

Ersta Sköndal University College

Stockholm, Sweden

Email: anders.moller@esh.se

\begin{abstract}
This is a qualitative study based on statements by administrators in the dementia sector in Norwegian local authorities. The aim of the present study is to investigate the arguments for and barriers to the allocation and organization of support contacts for people with dementia and their families. Various services are needed to help these families from being isolated. 'Support contacts' can be one such service, yet the local authorities rarely use them in the Norwegian dementia-care sector and little is known about why that is so. Support contacts are 'paid friends' and their tasks can be compared to respite carers or volunteers in other Western countries. The data was gathered from interviews with 35 informants (34 women and one man, aged 35-66 years) during 2011, from 32 local authorities in Norway. The analysis of data involved a qualitative content analysis. Three main categories emerged: 'knowledge', 'accessibility', and 'management'. 'Knowledge' describes the range of an administrator's familiarity both with dementia and with the legislation concerning the offering of a support contact to families with dementia, and it has two subcategories: 'formal knowledge' and 'experiential knowledge'. The category of 'reaching out' describes the circumstances that lead families with
\end{abstract}


dementia to apply for help and contains the subcategories of 'supplying information' about the service and 'characteristics of target group' receiving a support contact. The category of 'management of services' describes the various ways in which a supporter service may work satisfactorily and contains the subcategories 'recruitment' and 'organization'. In conclusion, the administrators consider support contacts to be a valuable service. The authors conclude that managers of local authorities need to organize their departments in a way that administrators will have sufficient knowledge about making the service available and supporter contacts will receive the necessary guidance and knowledge to maintain the service effectively.

Keywords: accessibility, dementia, health promotion, public health, services

\section{Introduction}

The majority of people suffering from dementia in Norway live in their own homes with the assistance of close family members (Engedal \& Haugen, 2009) until the later stages of the disorder. Caring for a family member with dementia is associated with a risk of developing health problems oneself because of the burden of caring obligations. In addition, as a consequence of having a member of the family with dementia, the primary familial carer as well as the person with dementia may become socially isolated (Ulstein, Bruun Wyller \& Engedal, 2007; Brodaty \& Donkin, 2009). The present study focuses on Norwegian experiences of dementia care.

From a public-health perspective it is important to provide a variety of assistance initiatives to these families during the entire progress of the disease in order to maintain personal activities and to prevent social isolation and thereby to promote their general health (Holley, 2007). It is well known that intellectual and social stimulation may both delay the impairment of the disease and enhance the quality of life (Engedal \& Haugen, 2009). The local authorities may choose the best way to help these persons, and a support contact (in Norwegian støttekontakt) can be one such service, either by itself or in combination with the other measures listed in the Social Service Act (HOD, 2006). This support-contact service is not new, but it has been more frequently allocated to people with a disability in general and to people with psychiatric disorders in particular (Norwegian Board of Health Supervision, 2008). Until recently, the focus on the services to families with dementia has been on nursing homes, medical treatment, cognitive aspects, and the impact on carers and their experiences. Formal help and assistance may help the persons with dementia as well as the carers to take part in everyday life and to maintain a satisfactory level of participation in society. Blackman et al. (2003) and Brorsson et al. (2012) have also shown that both the availability of access to public spaces and the physical environment affect the dementia patient's functioning in daily life.

According to the recommendations of the Norwegian Directorate for Health and Social Affairs (2005-2006) and the Government's Dementia Plan (2008), a strategy is needed to develop different services to make a social life more feasible for families with dementia. This aim is line with the barrier-free principles of Universal Design, where the overarching objective is promote the health of all persons, regardless of one's age or abilities (Story, Mueller \& 
Mace, 2001). Norwegian legislation as well as the Dementia Plan proclaims that anyone in need of personal or practical help in their daily life, due to disability, disease, age or some other reason may be deemed eligible to receive support from the local authorities, either to prevent social problems from arising or to alleviate them. This article uses the term 'supporter' to identify someone fulfilling the role of support contact (HOD, 2006). Supporters are supposed to replace neither professionals nor volunteers, but are instead meant to provide a supplementary service (Norwegian Board of Health Supervision, 2008). This service can also, if necessary, be offered to carers and people who have been given a day-care placement or a place in an institution, and there is no time limit on the hours that the supporter service may supply. However, the offer is made without any direct relation to the specific needs of the family in question, and it is of a more or less routine character (Norwegian Board of Health Supervision, 2008). In Norway the supporters are deemed to have the following functions: to help the supported person to participate in social, cultural, and sporting activities, to be a social contact or someone to talk to or to go shopping with, and to provide some respite to the primary carers. Supporters neither provide treatment nor require formal education or training, and are often usually hired part-time by the local authorities on a self-employed basis. In Norway, supporters are 'paid friends' with a low salary, and their tasks can be compared to those of respite carers, befrienders or voluntary workers in Norway and other Western countries. In the Nordic countries, the groups of people deemed eligible to receive a supporter are more or less the same, though in Sweden there is an age limit of 65 years for new applicants (Svensson, Ekvall \& Storfält, 2007).

The supporters can assist the person to maintain earlier activities and can be a link to society and thus help to prevent social isolation. In addition, they can also give the primary carers some time to keep up with their own activities. The service can also be group-based if it is suitable for the people who receive the service. Studies confirm that supporters are a valuable and important service and may be a helpful supplement to other services offered to families with dementia (Jansson, Almberg, Grafström \& Winblad, 1998; Bjørge, 2004), such as a day-care centre, or a short-term or full-time institutional placement. However, Norwegian dementia care rarely uses supporters: only 34 per cent of the 434 Norwegian local authorities offer this service to persons with dementia or their carers and in total 317 persons with dementia received this service in 2007. Of these 317 persons, 52 were under 65 years and 75 of the 317 persons also had a placement in an institution (Westerberg, 2009). Beyond these numbers, little is currently known about why Norwegian dementia care uses supporters so rarely or why there are these differences between the local authorities (Westerberg, 2009).

Therefore, in this study the focus is on administrators in the local authorities and how their knowledge and experience inform them on how they can contribute to maintaining a link between families with dementia and society, and consequently decrease the health problems associated with the isolation that these families experience. Both research (Jansson et al., 1998; Bjørge, 2004) and the Norwegian Government's Care Plan 2015 (2005-2006), including its sub-plan (2008), recommend the use of supporters. It is, therefore, important to investigate why local authorities offer supporters so rarely and, if they do, why administrators of different local authorities do so in markedly different ways. This study has applied a qualitative approach to examine these issues. More specifically, certain qualitative methods are advantageous because they describe the subjects' perceptions of their work in 
their own words, and these perceptions are at the core of this study's objectives (Karlberg, Hallberg \& Sarvimäki, 2002).

\section{The Study}

The aim of the present study is to investigate what administrators take to be the arguments for and barriers to the allocation and organization of support contacts for people with dementia and their families. On the basis of a previous study (Westerberg, 2009), we chose to ask 32 Norwegian local authorities at the municipal level, representing eight of the 19 counties in Norway, with different experiences of using the supporter service in Norway to participate in the study. The criteria for participation of the individual administrator in the interview study were as follows: experience of being an administrator in a position of authority to allocate services and of having the responsibility for case management of all kinds of services within health care or home care in general or dementia care in particular; knowledge about dementia; and substantial experience of being an administrator or experiences of working in dementia care for at least two years, of both. We also selected local authorities that represented cities as well as those that represented smaller communities in the countryside, with the result that this study dealt with variations in population size between 1300 and 600 000. These local authorities represented a range of experiences in using supporters, and some of them even had no experience at all with the supporter service in dementia care. Administrators from these care services were contacted by telephone and were asked to participate in this study. A total of 35 informants (aged between 35-66 years, all women except one) were interviewed during 2011. All of the informants were administrators and had been involved in managing services in general for persons with dementia. No one declined to participate in the study.

Following ethical approval by the Regional Committee for Ethics in Medical Research, Southern Norway, we collected the data with qualitative interviews using guide that comprised the thematic questions focusing on the informants' experiences of the kind of services families with dementia need during the entire course of the disorder, on what the local authorities' duties are towards these families, and on how the local authorities perform these duties. Depending on the replies received, the interviewer followed new ideas raised by the informants by asking further questions in order to obtain additional information. One of the authors (AJ) carried out the interviews were carried out in a conversation-based form. The interviews lasted for approximately 45-55 minutes and were recorded. (One interview lasted for only ten minutes owing to the informant's lack of experience.) They were mostly carried out at the informants' work place at a time and date convenient for them, though eight interviews were carried out on the telephone to save time and expense. Within a week after each interview a typist transcribed the complete recorded interviews verbatim. One of the authors (AJ) performed a quality-control check of the transcripts by listening to the tapes while reading the interviews.

Both authors analysed the transcribed interviews. Manifest qualitative content analysis (Graneheim \& Lundman, 2003) was applied to the interviews and carried out in the following stages. First, the authors read the text carefully several times to gain an overall impression, identified the words and sentences expressing a central meaning, and systematically condensed the data while being careful not to alter the original meaning. In the next stage, the 
authors assigned a code to the relevant phrases that identified their content. In the third and final stage, the categories were created. These consisted of groups of codes according to the themes in the interviews.

\section{Findings}

The findings in this study describe the variations of possible explanations for and barriers to the allocation and organization of support contacts for people with dementia and their families. There were three categories. The first category, knowledge, describes the variations in administrators' knowledge of dementia and of the laws regarding the allocation and organization of supporters to families with dementia. This category is divided into two subcategories: formal knowledge and experiential knowledge. The second category, reaching out, describes the variations in the process that leads to families with dementia applying for the service, and it has two subcategories: supplying information about the service and characteristics of target group allocated a supporter. The third category, management of the service, describes the variations of articulated reasons or arguments for and barriers hindering the allocation and organization of supporter services. This third category contains two subcategories: recruitment and organization. Each of the categories will be described below with excerpts from the interviews.

\section{Knowledge}

The category of knowledge and two sub-categories of formal knowledge and experiential knowledge cover the extent of the informants' formal knowledge of the legislation that governs the supporter service and their formal and experiential knowledge about families with dementia. These aspects give rise to their offering a variety of different services.

\section{Formal knowledge}

The informants' formal knowledge about dementia and the law granting the supporter service varied. Twenty-five informants were registered nurses, two were nursing-assistant graduates, and the other eight had various college degrees within the area of health studies. Five informants had formal knowledge about health legislation in general. Most of the informants had completed further studies, branching out into geriatrics, psychiatry, and management, and 14 informants had formal knowledge of dementia. Those informants saying they had formal qualifications in the care of dementia (and some of those without formal qualifications) stated that it was important to provide families with dementia with services that were individually tailored. According to these informants, they believed that there should be a focus on providing relief and information to these families.

Moreover, the informants who stated that they knew nothing about the supporter service also had no formal knowledge about health legislation. These informants held a variety of misconceptions. Some believed that the service was not allowed to be offered to persons with dementia or their carers, that the service was limited to only a few hours a week, or that it could only be used for recreational activities and not in cases where a person would be unable to participate in group activities. Moreover, some thought that it could not be offered to those with access to institutions or placements in day-care centres. For these reasons the families in question were not being given the service. 
Furthermore, the informants without formal knowledge about legislation and dementia stated that this service was not being offered because a lack of resources forced them to give priority to the many younger people who were in need of a supporter. However, administrators with formal knowledge of the legislation maintained that no application would be rejected, even if the budget had been used up. Another opinion held by some administrators was that while supporters provide a valuable service to carers, they are nevertheless unskilled workers who cannot provide care to persons with dementia. Accordingly, these administrators' practice was to refer these families to already established services, and to encourage these families to apply to receive an allowance to pay family carers, an institution or a day-care placement. Those informants who had no formal education about the relevant legislation and who tried to apply for supporters for families with dementia revealed that they had been rejected by other administrators and did not know how to appeal against the decision through the county council. As one informant expressed:

We do not use supporters for care of the elderly. Families with dementia may apply, but I do not know if it would be granted. It is outside my remit.

Furthermore, according to the informants without formal knowledge about legislation, they had received guidance from the county council about how to manage the service, and they described this experience as positive. Some informants' eyes had also been opened to the supporter service by carers whose request for a supporter had been initially rejected but later granted following a successful appeal to the county council.

\section{Experiential knowledge}

This subcategory captures the informants' descriptions of a range of experiences with the supporter services for families with dementia. The findings show that there were some local authorities that offered the service and had a system for organizing the service. Other local authorities offered this service to a few families with dementia, but lacked the procedures for organizing the service. Still others had no experience of using this service for these families. According to the informants who had experience with the use of supporters in the care of dementia, carers and persons with dementia appreciated the supporters' help and the informants wanted to increase the use of this service. However, it must be noted that most of them also stated that the service did not work if the person with dementia has reached an advanced stage because the tasks become too burdensome for a supporter with no formal qualifications. For that reason the use of supporters would not be appropriate at the later stages of the disorder.

According to the informants with experiential knowledge the use of supporters for these families was aimed at relieving their carers, preventing isolation, maintaining previous activities, and preventing agitation in the person with dementia. They also felt that it could be a complement to other services, such as a placement in an institution or day-care centre. These informants also estimated that this kind of service could be a cheaper alternative to those mentioned above. Other informants with experiential knowledge remarked that it was easier for some persons with dementia who were not interested in using a day-care centre to accept supporter services, and that it could delay a placement in an institution. Some persons with dementia were in need of a supporter for a few hours a week and others several hours, but the service 
could be increased when needed if it was working well. In cases of people with dementia with severe behavioural problems, the informants needed to be able to supply skilled supporters with formal qualifications and experience of dementia.

One of the informants who had experience with the use of supporters in the care of dementia stated that the service works very well, that it is flexible and easy to adapt to individual needs, and that if the supporter is the same person who comes every time, it creates security both for the person with dementia and for his or her carers.

I think this service is very good for carers and persons with dementia, because it is the same person who comes to the family every time. So carers become very confident that the person with dementia is having a good time and as they become more familiar with the supporter the carers will not be so afraid of leaving home and staying away for the whole session. For the persons with dementia who may not benefit from other services, such as day care, or do not fit into groups, this is a very good service. It is also a low-threshold service, which makes it easier to accept it.

Other experiences with the supporter service that informants shared with us were that supporters should know all they can about the person with dementia, because this would make it easier to understand him or her. The family's needs must also be identified and the supporter and the person with dementia should preferably be matched according to age and gender.

\section{Reaching out}

Under this category, reaching out, the informants described how they sought to contact the families in order to provide them with information about the services in general and how the supporter service could be made available to them. The variations in this process are described through the subcategories supplying information to families with dementia and characteristics of target group with dementia who were receiving a supporter service.

\section{Supplying information}

This subcategory includes statements by the informants that described how information to families with dementia about supporters and services in general was provided through various channels such as the Internet, local newspapers, brochures, courses for carers, information stalls, posters, libraries, local radio channels, senior centres, and through other supporters or carers. They also spoke about using standardized forms where people could apply for all the services as being useful. Reaching these families is a challenge, according to the informants, but the families' receiving information early in the course of the disorder is important in order to prevent carers from burning out, and so that people with dementia will be able to stay at home for as long as possible. They often receive applications from carers when the person with dementia has progressed so far that the need for an institutional placement is unavoidable.

According to the informants, the information these families receive depends on the health-care personnel's knowledge both about the available services and about the disease itself. To improve the distribution of information to these families, local authorities could establish a contact person who is responsible 
for coordinating services or for mapping out districts with many people over 75 or 80 years in order to identify needs on a general basis and to provide information about services. This effort had resulted in new cases of dementia being detected. But according to the informants the outreach service to the elderly had been discontinued because of financial difficulties with the local authorities, and that dementia teams and dementia coordinator positions had been cut for the same reason, resulting in fewer requests for services. Moreover, according to the informants, they had recently received several applications for supporters from elderly people, when normally only younger people apply. Other informants reported that they do not provide information about the supporter service to families with dementia because the local authority has a focus on offering day-care centre placement as a priority service for these families. The informants stated that they also believed that persons with dementia do not benefit from support services and for that reason do not inform them about the service. Still, one informant commented on how the supporter service is starting to become better known:

It has not been widely known that families with dementia can apply for a supporter, but it is now beginning to be known that these families can apply for this service. Other groups often do apply for this service.

\section{Characteristics of target group}

Some characteristics of those families that are more frequently assigned a supporter are that neither the person with dementia nor the carer is more than 65 years old, that the person with dementia has special interests, and that there is no day-care centre in the neighbourhood. Another characteristic is that the person with dementia is in need of a high degree of physical activity, particularly when he or she is placed in an institution where the staff are unable to accompany him or her for a sufficient number of walks, or if the person with dementia is troubled upon coming home to a 'no-care' situation after a session at a day-care centre. The informants also added that men were sometimes assigned a supporter because the activities at the day-care centre were not orientated towards men.

Furthermore, the informants remarked that the carers' need for relief could be a reason for granting a supporter, as could the needs of these families to maintain social activities and interests. The informants also described how cooperating with many of the families could be a challenge for administrators: it is time-consuming, some carers and persons with dementia have difficulty accepting help, and there is often a long process before these families accept it. In many cases people believe that services are not for them and so they do not apply. Their belief is linked to their level of knowledge, which varies among families with dementia. The informants were using home visits to enter into a dialogue with these families and they described the supporter service as a low-threshold service, that is, a service that the person with dementia and the carer more easily accept. Persons with dementia and their carers seem to be more positive about supporters than about the other kinds of services offered. However, for some families it is still stigmatizing to receive help, even though they greatly need it. One informant remarked on the issue of stigmatization:

Now we have some younger persons with dementia, and they are not elderly. They should have the same rights as other young disabled persons. But there are still some differences, though I think this has started to change. There is more openness about dementia now and 
people know a little more about what dementia is, but we are not quite at the place yet where all illnesses can be regarded equally.

\title{
Management of services
}

The category of management of services covers the statements by the informants that point to the variation they had seen in the process of recruiting and organizing the supporter service. This is described in the subcategories recruitment and organization as they relate to the allocation of the service.

\begin{abstract}
Recruitment
With respect to recruitment, some informants described how difficult it was to recruit supporters for the local authorities and how it was particularly difficult to recruit supporters for the elderly and persons with dementia, but they also mentioned that becoming a supporter has been a popular choice. According to the informants, the local authority often recruits supporters through a family network, so that persons with dementia do not have to deal with a stranger. In contrast, other informants said that they recruited supporters neither from within the family nor from its network because this would drain resources away from the network of the family. The informants who had experience of using supporters stated that it was not so difficult to recruit supporters, and the informants had also tried to recruit supporters who could work with several families with dementia. The supporters were recruited by the local authorities from a number of sources, as was described above under the subcategory of supplying information.
\end{abstract}

Furthermore, the interviewees with experience of using supporters stated that it was easier to recruit supporters among people over 60 and women, and that they interview prospective supporters and check their references from previous employers before employing them. Many of the supporters had experiences of dementia from their own family or friends and some also had some formal knowledge about the disorder. Health-care personnel with reduced capability due to illness or who have become unemployed have on occasion contacted administrators and expressed a desire to be a supporter and have subsequently been hired. The informants stated that many supporters continue to be a supporter for years, while others quit after a short time. The informants also stated the difficulty in recruiting supporters because the payment is low, while others said that payment had not been the decisive reason for the supporter's commitment, but rather it was their need to be an important person for others. According to the informants the payment could vary and if the payment were to be too high it might attract people who would not be suitable supporters. Other informants noted that carers often recruited supporters through their own family network. For these carers, it was important that there a payment is involved because it makes it easier to ask others to fulfil the tasks as a supporter.

The informants with experience of using supporters expressed how they wanted to organize and give guidance to supporters in a better way. They believed that this would make supporters continue to support families with dementia. They reported that if the supporters received information and guidance, it influenced recruitment in a positive way and the service in general worked better for those who were receiving it. As one informant observed:

It has become easier to recruit supporters now because the administrators of the supporter service are very enthusiastic and have 
created a system of supervision and guidance. It has been difficult to

recruit supporters for some groups, but not necessarily for the elderly.

\section{Organization}

The subcategory of organization captured how the informants described, with much variation from one local authority to another, how the local authorities manage supporter services and how they guide and introduce the supporters to the tasks.

Though each of the informants held an administrative position within health care, some of them were not executive administrators for the supporter service. The supporter service was instead managed by people in different departments within the local authorities, some of whom had formal knowledge neither of dementia nor of the laws governing health care. This way of organizing the supporter service within the local authority led to a lack of cooperation and understanding of each other's fields. The administrators believed that this was one of the reasons why the service was not offered regularly to families with dementia. The informants had found that the healthcare personnel gained more knowledge and information about the supporter service after there had been a successful reorganization where several units had been placed under the same department.

According to the informants who were providing this service to families with dementia, they had introduced the supporters to the families and given information and guidance to the supporters prior to the start of the service. They also described their having had regular meetings with the supporters' once or twice a year, and added that the supporters could contact them if necessary.

Other informants described that the local authority had organized regular group meetings with the supporters, so that they could receive guidance together, and that all the supporters had someone to contact when they were in need of guidance. These local authorities also give the supporters an opportunity to attend both training with other staff about dementia and training specifically for carers. Furthermore, they had set up their own procedures for the payment of salary and other expenses in connection with the supporters' performance. The informants also expressed that they were not aware of any official procedures relating to this. There were also informants who informed us that they did not know how the supporters were provided with guidance because other units in the local authority were responsible for providing it. However, these units did not necessarily have specific knowledge about dementia, and the informants who had experienced the usefulness of the service and guidance for the supporters found this lack of knowledge to be confusing.

Another way of supporting the supporters was to put them in touch with staff who have experience of dementia. Some supporters also submitted a report every month and the informants described that they had regular contact with the families. Other informants also stated that they did not follow up on the service, and lacked information on whether the service was working or not.

It depends on the assignment and individual qualifications for what kind of guidance supporters need. Some are quick to ask for guidance, while you never hear a word from others, until suddenly they quit and later on 
it turned out that the challenges were too great for the supporter. So this

is a challenge for me as an administrator to which I have to respond.

\section{Discussion and conclusions}

The aim of the present study has been to investigate the informants' statements of arguments for and barriers to the allocation and organization of support contacts for people with dementia and their families. The central issue of the present study is that knowledge about support contact and dementia is crucial for providing this service to families with dementia and that this knowledge can be undeveloped. There is need for improvement in the further education of administrators responsible for the care of dementia at the local level. Another issue revealed by the data is that reaching out to these families with dementia was both demanding and time-consuming. Lastly, the reason why this supporter service is allocated in so many different ways has to do with the management of the services in the local authorities.

Local authorities do not make this supporter service sufficiently available for families with dementia, and they have not found an optimal organization for managing it. Once again, the degree of availability was connected to the informants' and other administrators' level of knowledge of the laws that regulate the health-care services for persons and families with a dementia disorder and to their experience with the supporter service. These findings are in line with a survey in Norway by Westerberg (2009) that showed that only a minority of communities in Norway offer the supporter service. Selbæk and Høgset (2010) have shown that the kind and quality of service that is offered to the population depend on the individual knowledge of the administrators. An international review of the literature shows that the supporter service is also not much utilized in other countries, and that there is a lack of quality research in this area, according to Lee and Cameron (2006). Axelsson and Bihari Axelsson (2006) and the Norwegian Board of Health Supervision (2008) have also shown that the organizational structure of the local authorities and attitudes among health-care professionals about what makes for a good service in the care of dementia affect the choice of services.

Furthermore, this study shows that a few of the administrators who were managing this service for families with dementia did not have sufficient knowledge of the law and ordinary case procedure within health care, since, according to these informants, this service was not for families with dementia. This study also shows that the kinds of experiences the informants had of the supporter service had an impact on the allocation and development of the service. Furthermore, the informants stated that supporters could be complementary to other services and could be developed further. The service provided continuity and could prevent social isolation, which a number of studies have stressed as important in promoting health (Holley, 2007; Brodaty \& Donkin, 2009; Hardy \& Kingston, 2009). A review study by Schoenmakers, Buntinx, and DeLepeleir (2010) confirms that continuity in dementia care is important. Temporary respite care scheduled only for a short time increases the burden on carers. However, the present study has shown that, according to the informants, supporters may not be a suitable kind of service later in the course of the disease because the tasks at that point are too difficult for an unskilled or uneducated person to handle. Silverstein Wong and Brueck (2010) have also pointed out in their study that persons with dementia require educated health-care personnel in the later stage of the dementia disorder. 
Furthermore, the present study shows, on the one hand, that those informants who had experience of the service and of the guidance that the supporters received stated that it was not difficult to recruit supporters, and that families with dementia often applied when they had received information about the service. On the other hand, informants who had no experience of offering this service declared that supporters were no use for families with dementia and, in any case, supporters were difficult to recruit and it would be a challenge to get the information about the services to these families. However, as it turns out, even when administrators do know about legal and administrative procedures and about dementia, many families with dementia still do not receive this service (Norwegian Board of Health Supervision, 2008). Only 317 people with dementia received this service in 2007 in Norway (Westerberg, 2009), and many of them were under 65 years of age. This situation does not seem to have changed, according to a survey by Eek and Kirkevold (2011). In line with these findings, our study shows that the characteristics of the family, such as age and gender, and other characteristics as described in the findings, affect the allocation and choice of services.

This study also illustrates how organizational structures and cooperation within the local authorities affect the quality and availability of services. Some informants described how the local authorities divided the administrator's tasks in such a way that different administrators managed the services that families with dementia received, and this put these families at risk of not being prioritized for economic reasons by administrators who lacked expertise in the law and in dementia. Furthermore, local authorities who had organized joint meetings within the various departments had contributed to bettering administrators' understanding of other users' needs and consequently also those of the families with dementia. How services are organized and how local authorities cooperate with the users affect the quality of services and their availability, a finding that other studies have also confirmed (Ryan, Nolan, Enderby \& Reid, 2004; Axelsson \& Bihari Axelsson, 2006; Öhman, Josephsson \& Nygård, 2008; Wihlman, Lundborg, Axelsson \& Holmström, 2008; Hardy \& Kingston, 2009).

One conclusion that we can draw from the present study is that services are not available to everyone, though Norwegian law (HOD, 2006) has stipulated that they should be. Further, neither the principles of Universal Design (Story, Mueller \& Mace, 2001) nor the Norwegian Law on the prohibition of discrimination and accessibility based on reduced functional ability (BLD, 2009) is being fulfilled. In order to address this shortfall, local authorities must focus on the collaboration between different professions and departments. Specialization within welfare services makes it difficult and challenging to provide the comprehensive services needed by families with dementia. Bihari Axelsson and Axelsson (2009) have emphasized this point, and it is the intention of the new public-health law implemented by the Norwegian Ministry of Health and Care (2012) to provide these comprehensive services.

Moreover, this study has also shown that in order to develop the supporter service, organizational structures must have administrators who can follow up on the supporters and provide guidance and education, both of which can affect the quality of services and provide the opportunities for improving the recruitment of supporters and counteracting supporter resignations. Other studies have confirmed this finding (Severinsson \& Kamaker, 1999; Ryan et al., 2004; Testad, Mikkelsen, Ballard \& Aasland, 2010). 
The present study has used qualitative methods (content analysis) to collect and analyse the data (Graneheim \& Lundman, 2004). The choice of method was motivated by the lack of previous studies on the use of supporters in the care of dementia. The qualitative method enables the researcher to focus on the informant's point of view, and the present study depicts the informants' own descriptions and stories, which are fundamental for understanding why this service is not offered by all local authorities and where it is offered why it is not provided to more families with dementia. Knowledge of why this service is offered so differently from local authority to local authority is difficult to address with quantitative methods, and qualitative methods are helpful for improving our knowledge of phenomena in areas where little is known, as Dellve, Abrahamsson, Trulsson, and Hallberg (2002) have argued. Even if the findings cannot be generalized in a statistical sense, our findings are transferable to other contexts (Malterud, 2001; Flyvbjerg, 2004), such as other groups of patients and other local authorities in Norway, and perhaps other countries. Thus the findings of this study can contribute to the development and organization of services in a more holistic way that would help to promote the health in families coping with dementia.

This study chose a strategy that included informants of all kinds, since content analysis aims to describe variation. With 35 informants included from 32 local authorities with different population sizes, representing cities as well as smallcommunity municipalities located in the countryside, coming from eight counties, informants with different levels of formal knowledge and experience (or lack of experiences), working in different organizational structures, and of various ages, we believe that we have made it possible to describe a broad variation of experiences that strengthens the validation of the findings (Patton, 2002). In order to contribute to the trustworthiness of the findings, this study has presented quotations in the text and the authors have analysed the data together and discussed critically the categories and level of abstraction (Lincoln \& Guba, 1990). One limitation with the present study is that only one administrator (in one cases two administrators) from each local authority was interviewed. This makes it impossible to interpret the results as the definitive or official views of the local authorities. Rather, the ambition with the present study was to find arguments for and against using supporters and these were presented by the individual administrators.

\section{Acknowledgements}

This study was supported by the Nordic School of Public Health, Gothenburg, Sweden, and Ageing and Health, Norwegian Centre of Research, Education and Service Development, Norway.

\section{References}

Axelsson, R., \& S. Bihari Axelsson, S. (2006). Integration and collaboration in public health. International journal of health planning, 21, 75-88. 
Bihari Axelsson, S., \& Axelsson, R. (2009). From territoriality to altruism in interprofessional collaboration and leadership. Journal of Interprofessional Care, 23(4), 320-330.

Bjørge, T. (2004). Friminutt for pårørende [A break for carers]. Tønsberg: Forlaget Aldring og helse.

Blackman, T., Mitchell, L., Burton, E., Jenks, M., Parsons, M., Raman, S., \& Williams, K. (2003). The accessibility of public spaces for people with Dementia: a new priority for the 'open city'. Disability \& Society, 18(3) 357-371.

BLD, Barne-, likestillings- og inkluderingsdepartmentet. [Ministry of Children, Equality, and Social Inclusion]. (2009). Lov om forbud mot diskriminering på grunn av nedsatt funksjonsevne [Law on the prohibition of discrimination and accessibility base $d$ on reduced functional ability] Retrieved from: http://www.lovdata.no/cgiwift/wiftldles?doc=/app/gratis/www/docroot/all/nl20050 603033.html\&emne=diskrimineringslov ${ }^{\star} \& \&$

Brodaty, H., \& Donkin, M. (2009). Family caregivers of people with dementia. Dialogues in Clinical Neuroscience, 11(2), 217-228.

Brorsson, A., Öhman, A., Lundberg, S., \& Nygård, L. (2012). Accessibility in public space as perceived by people with Alzheimer's disease. Dementia, 10(4), 587602.

Dellve, L.K., Abrahamsson, H., Trulsson, U., \& Hallberg, LR-M. (2002). Grounded theory in public health research. In Qualitative research methods in public health research, Hallberg, L.R-M. Lund, (ed.). pp. 137-73. Lund: Studentlitteratur.

Eek, A., \& Kirkevold, Ø. (2011). Nasjonal kartlegging av tilbud til personer med demens 2010-2011. [National survey of services offered to persons with dementia]. Tønsberg: Forlaget Aldring og helse.

Flyvbjerg, B. (2004). Five misunderstandings about case-study research. In Qualitative Research Practice, Seale, C., Gobo, G., Gubrioum, J.F., \& Silverman, D. (eds.). pp. 420-434. London: Sage.

Graneheim, U., \& Lundman, B. (2004). Qualitative content analysis in nursing research: concepts, procedures and measures to achieve trustworthiness. Nurse Education Today, 24, 105-112.

Hardy, S., \& P. Kingston. (2009). A dementia support worker service evaluation. Centre for Aging and Health, England: Staffordshire University.

Holley, U. A. (2007). Social isolation: a practical guide for nurses assisting clients with chronic illness. Rehabilitation Nursing, 32(2), 51-6.

HOD, Helse og omsorgsdepartementet. [Ministry of Health and Care Services]. (20052006). Mestring, mulighet og mening, framtidas omsorgsutfordringer [Coping, possibilities and meaning, future demands on care]. Oslo: Retrieved from http://www.regjeringen.no/nb/dep/hod/dok/regpubl/stmeld/20052006/stmeld-nr25-2005-2006-.html id=200879

HOD, Helse og omsorgsdepartementet. [Ministry of Health and Care Services]. (2006). Loven om sosiale tjenester $\$ 4-2$, [The law on social services], Retrieved from http://www.lovdata.no/all/tl-19911213-081-004.html

HOD, Helse og omsorgsdepartementet. [Ministry of Health and Care Services]. (2008). Demensplan 2015, [The Norwegian Government's Dementia Plan 2015]. Retrieved from http://www.regjeringen.no/upload/HOD/

Dokumenter\%20KTA/DementiaPlan2015.pdf 
HOD, Helse og omsorgsdepartementet. [Ministry of Health and Care Services]. (2012). Lov om folkehelsearbeid, [Law on Public Health]. Retrieved from http://www.lovdata.no/ltavd1/filer/nl-20110624-029.html

Jansson, W., Almberg, B., Grafström, M. \& Winblad, B. (1998). The Circle model: support for relatives of people with dementia. International Journal of Geriatric Psychiatry, 13(10), 674-81.

Karlberg, I., Hallberg, L.R-M. \& Sarvimäki. A. (2002). Introduction and aims of the book - public health and research on public health. In Qualitative methods in public health research, Hallberg. L.R.-M. (ed.). pp. 13-34. Lund: Studentlitteratur.

Lee, H. \& Cameron, M. (2006). Respite care for people with dementia and their carers. The Cochrane Library. Issue 1.

Lincoln, Y. S. \& Guba, E. G. (1990). Naturalistic inquiry. Newbury Park: Sage Publications.

Malterud, K. (2001). Qualitative research: standards, challenges and guidelines, The Lancet, 123, 117-126.

Norwegian Board of Health Supervision (2008). Avlastning og støttekontakt - tjenester med betydning for et bedre liv! [Respite care and support contact: services that improve the quality of life!] Oslo: Helsetilsynet.

Patton, M, Q. (2002). Qualitative Research \& Evaluation Methods, (3ed.). London: Sage.

Ryan, T., Nolan, M., Enderby, P., \& Reid, D. (2004). 'Part of the family': sources of job satisfaction amongst a group of community-based dementia care workers. Health and Social Care in the community, 12(2), 111-118.

Schoenmakers, B., Buntinx, F., \& DeLepeleire J. (2010). Supporting the dementia family caregiver: the effect of home care intervention on general well-being. Aging \& Mental Health, 14(1), 44-56.

Selbæk, G. \& Høgset, D. L. (2010). IPLOS og kartlegging av tjenestebehov hos hjemmeboende med kognitiv svikt. [IPLOS (Statistics of individual-based treatment and care) and a survey of the needs for services for people with cognitive impairments living at home]. Hamar: Alderspsykiatrisk forskningsnettverk, Sykehuset Innlandet.

Severinsson, E.I., \& D. Kamaker. (1999). Clinical nursing supervision in the workplace: effects on moral stress and job satisfaction. Journal of Nursing Management, $7(2), 81-90$.

Silverstein, N.M., Wong, C.M., \& Brueck, K.E. (2010). Adult day health care for participants with Alzheimer's disease. American Journal of Alzheimer's Disease \& Other Dementias, 25(3), 276-283.

Story, M. F., Mueller, J., \& Mace. R. (2001). The Universal Design file, designing for people of all ages and abilities. Raleigh: North Carolina State University.

Svensson, C., Ekvall, M., \& Storfält. R. (2007). En obetald vän i behov av stöd. [An unpaid friend in need of support]. Gothenburg: University of Gothenburg.

Testad, I., Mikkelsen, A., Ballard, C., \& Aarsland, D. (2010). Health and well-being in care staff and their relations to organizational and psychosocial factors, care staff and resident factors in nursing homes. International Journal of Geriatric Psychiatry, 25(8), 789-797. 
Ulstein, I., Bruun Wyller, T., \& Engedal, K. (2007). The relative stress scale: a useful instrument to identify various aspects of carer burden in dementia? International Journal of Geriatric Psychiatry, 22(1), 61-67.

Westerberg, T.H. (2009). Gode tilbud i demensomsorgen: demensteam, dagsenter, pårørendeskoler. [Good services in the dementia-care sector: dementia team, day care, and schools for caregivers]. Tønsberg: Aldring og helse.

Wihlman, U., Lundborg, C. S., Axelsson, R., \& Holmström, I. (2008). Barriers of interorganisational integration in vocational rehabilitation. International Journal of Integrated Care, 8(19 June), 1-12.

Öhman, A., Josephsson, S., \& Nygård, L. (2008). Awareness through interaction in everyday occupations: experiences of people with Alzheimer's disease. Scandinavian Journal of Occupational therapy, 15(1), 43-51. 